\title{
O PRINCÍPIO DA INFORMAÇÃO NO CADASTRO AMBIENTAL RURAL E O PLANEJAMENTO DE POLÍTICAS PÚBLICAS
}

\author{
Inê Aguiar Rocha ${ }^{1}$ \\ Universidade Federal do Pará \\ inerochaa@hotmail.com \\ Marise Teles Condurú ${ }^{2}$ \\ Universidade Federal do Pará \\ marise@ufpa.br \\ Maria do Socorro Almeida Flores ${ }^{3}$ \\ Universidade Federal do Pará \\ saflores@ufpa.br \\ Gilberto de Miranda Rocha ${ }^{4}$ \\ Universidade Federal do Pará \\ gilrocha@ufpa.br
}

\section{Resumo}

Estudo sobre a informação ambiental que propicia a compreensão das condições ambientais existentes, com vistas a auxiliar a implementação de políticas públicas voltadas à proteção do meio ambiente, enquanto direito fundamental. Este trabalho tem como objetivo geral analisar o princípio da informação no Cadastro Ambiental Rural (CAR), considerando sua finalidade de integrar informações atuando no controle ambiental e auxiliando na formulação de políticas públicas. Para isso, foi realizada pesquisa qualitativa. Como resultados, constatou-se que a regulamentação infraconstitucional e a implementação do Sistema Nacional de Cadastro Ambiental Rural (SICAR) proporcionam um ambiente conflituoso em relação a transparência das informações ambientais. Concluise, portanto, que isso compromete a eficácia na implementação de políticas públicas voltadas a proteção do meio ambiente.

Palavras-chave: Informação ambiental. Políticas públicas. Desenvolvimento sustentável.

\section{THE INFORMATION PRINCIPLE IN RURAL ENVIRONMENTAL REGISTRATION AND PUBLIC POLICY PLANNING}

\begin{abstract}
The paper deals with environmental information as a subject that provides an understanding of existing environmental conditions to assist public policy implementation for environmental protection as a fundamental social right. The paper aims to analyze the principle of information in the public policy called Rural Environmental Registry (CAR). It takes its purpose to integrate information for environmental control and to assist the formulation of public policies. The research was based on qualitative research analysis. As an outcome, the paper shows that infraconstitutional regulation and the implementation of the National Rural Environmental Registry System (SICAR) provide conflicts in terms of environmental information transparency. The article concludes that such conflicts impacts public policies implementation effectiveness that aims environmental protection.
\end{abstract}

Keywords: Environmental information. Public policies. Sustainable development.

\footnotetext{
${ }^{1}$ Bacharel em Direito; mestranda do Programa de Pós-graduação em Gestão dos Recursos Naturais e Desenvolvimento Local na Amazônia (PPGEDAM) do Núcleo de Meio Ambiente (NUMA) da Universidade Federal do Pará (UFPA).

${ }^{2}$ Biblioteconomista, Doutora em Desenvolvimento Socioambiental pelo NAEA/UFPA, Professora do Programa de Pósgraduação em Gestão dos Recursos Naturais e Desenvolvimento Local na Amazônia (PPGEDAM), do Núcleo de Meio Ambiente (NUMA) da Universidade Federal do Pará.

${ }^{3}$ Bacharel em Direito, Doutora em Desenvolvimento Socioambiental pelo NAEA/UFPA, Professora do Programa de Pósgraduação em Gestão dos Recursos Naturais e Desenvolvimento Local na Amazônia (PPGEDAM) do Núcleo de Meio Ambiente (NUMA) da Universidade Federal do Pará (UFPA).

${ }^{4}$ Geógrafo, Doutor em Geografia Humana pela UNESP, Professor titular do Núcleo de Meio Ambiente (NUMA) da Universidade Federal do Pará onde atua no Programa de Pós-graduação em Gestão dos Recursos Naturais e Desenvolvimento Local na Amazônia (PPGEDAM).
}

(c) (1) () (2) Esta obra está licenciada sob uma licença

(c) ${ }_{\text {BY NC SA }}$ Creative Commons Attribution 4.0 International (CC BY-NC-SA 4.0). P2P \& INOVAÇÃO, Rio de Janeiro, v. 7, Ed. Especial, p. 101-117, jan. 2021. 


\section{ARTIGO}

INOVAÇÃo

\section{INTRODUÇÃO}

A Constituição Federal resguardou a proteção do meio ambiente ecologicamente equilibrado como um direito fundamental, impondo ao Poder Público e à sociedade o dever de preservar e defender o meio ambiente para as gerações atuais e futuras, incumbindo à legislação infraconstitucional a responsabilidade de regulamentar o tema. Nesse contexto, a proteção do meio ambiente, orientada pela implementação de políticas públicas, somente é efetivada com a participação da coletividade em conjunto com o Poder Público, ratificando a importância da informação ambiental para tal intento. A informação ambiental, enquanto direito fundamental, tem como propósito educar e situar a sociedade sobre a realidade existente, proporcionando uma participação ativa dos indivíduos em relação aos assuntos que envolvem o meio ambiente e seu equilíbrio.

Atualmente, frente ao cenário político-econômico de grandes problemas ambientais, faz-se necessário incentivar uma consciência ambiental que promova a tutela coletiva do meio ambiente equilibrado por meio da informação ambiental. O Código Florestal (Lei Federal $n^{0}$ 12.651/2012) regulamenta a implementação de instrumentos com o intuito de preservar o meio ambiente, dentre eles o Cadastro Ambiental Rural (CAR). De acordo com seu artigo 29, tal cadastro, mecanismo integrante do Sistema Nacional de Informação sobre o Meio Ambiente (Sinima), representa um "registro público eletrônico de âmbito nacional, obrigatório para todos os imóveis rurais, com a finalidade de integrar as informações ambientais das propriedades e posses rurais" (BRASIL, 2012, não paginado). O CAR forma uma base de dados para controle, monitoramento, planejamento ambiental e econômico e combate ao desmatamento.

A finalidade de integrar informações ambientais de imóveis rurais para a população em prol do desenvolvimento sustentável só é alcançada se os dados e informações forem transparentes e acessíveis. Sendo assim, o objetivo deste trabalho concentra-se em analisar o princípio da informação no CAR, considerando sua finalidade de integrar informações atuando no controle ambiental e auxiliando na formulação de políticas públicas.

Em que pese afirmar a pretensão de garantia do direito de livre acesso à informação, a regulamentação infralegal do Sistema Nacional de Cadastro Ambiental Rural (Sicar) estabelece determinadas restrições acerca da transparência do Cadastro Ambiental Rural, a exemplo da imposição de sigilo sobre os dados de identificação dos respectivos proprietários e possuidores rurais e eventuais dados patrimoniais cadastrados, opondo-se à Lei de Acesso a Informações Públicas. 


\section{ARTIGO}

INOVAÇÃO

É dever do Poder Público observar e ressaltar a importância da informação e sua efetivação para implementação de políticas públicas eficientes, pincipalmente quanto a dados que estejam relacionados ao combate e prevenção de danos ambientais. Sendo assim, a presente pesquisa justifica-se pela importância de se analisar se o intento do Cadastro Ambiental Rural está sendo cumprido na implementação de políticas públicas voltadas à proteção do meio ambiente. Para alcançar esse objetivo, foi realizada pesquisa de abordagem qualitativa, exploratória e de cunho bibliográfico, tendo sido investigado sobre a informação ambiental e a importância de instrumentos de políticas públicas, como o CAR.

O artigo está estruturado em cinco seções. Nesta introdução são apresentados o tema, a problemática, a questão de pesquisa, os objetivos e a metodologia para a realização da pesquisa. Na seção 2 aborda-se a questão ambiental na Constituição Federal brasileira, como direito fundamental; na seção 3 é mostrado o princípio da informação na seara ambiental, enquanto na seção 4 é discutida a informação ambiental no Cadastro Ambiental Rural e o planejamento das políticas públicas. Por fim, na seção 5 tem-se as considerações finais e as referências que fundamentaram a pesquisa.

\section{A CONSTITUIÇÃO FEDERAL DE 1988 E A PROTEÇÃO AMBIENTAL}

A necessidade de preservação e conservação do meio ambiente para todas as gerações é uma importante referência na defesa dos direitos ambientais. Ela foi introduzida no ordenamento jurídico nacional pela Constituição Federal de 1988, que traz a proteção ambiental permeando todo o texto constitucional em referências explícitas, naqueles dispositivos que contém a expressão "meio ambiente", e em referências implícitas encontradas nos dispositivos que tratam de setores ou sobre recursos ambientais (SILVA, 2019).

A Carta Magna promulgada em 1988 estabelece, em seu artigo $3^{\circ}$, objetivos fundamentais da República Federativa do Brasil, tais como: garantir o desenvolvimento nacional, erradicar a pobreza e a marginalização e reduzir as desigualdades sociais e regionais, promover o bem de todos, sem preconceitos de origem, raça, sexo, cor, idade e quaisquer outras formas de discriminação, e construir uma sociedade livre, justa e solidária (BRASIL, 1988, online). Observa-se um propósito complexo nas metas constitucionais, pois implicam em harmonizar aspectos ambientais, sociais, culturais e econômicos.

Ainda no âmbito constitucional tem-se a importância dos direitos fundamentais, permanentes e criados em um contexto histórico da sociedade, que tem como base a proteção da dignidade do ser humano. Tais direitos visam assegurar aos indivíduos, em sua proteção, o 
respeito à igualdade, à liberdade, à dignidade e ao direito ao meio ambiente ecologicamente equilibrado. Os direitos fundamentais foram inicialmente classificados pela doutrina em gerações de direitos e posteriormente em dimensões de direitos fundamentais, dada a inadequação do vocábulo geração, posto que não há eliminação entre elas, mas coexistência no plano do ordenamento jurídico dos estados nacionais; portanto, deve entender-se a classificação em dimensão de direitos e não em gerações de direitos.

As dimensões de direitos humanos e de direitos fundamentais integram a ordem jurídica baseando-se numa ordem histórica cronológica na qual os direitos passaram a ser reconhecidos como consequências dos movimentos sociais que pautavam as demandas sociais por respeito aos direitos humanos. Primeiramente, evidenciam a transformação de um Estado autoritário para um Estado de Direito, ressaltando as liberdades individuais em um panorama de absenteísmo estatal, frutos do pensamento liberal-burguês do século XVIII (LENZA, 2019).

Bonavides (2018) anota que tais direitos têm por titular o indivíduo e são oponíveis ao Estado, traduzindo-se como faculdades ou atributos da pessoa, ostentando uma subjetividade como atributo característico. Portanto, os direitos de primeira geração são reconhecidos como aqueles primeiros direitos conquistados pela humanidade, relacionados pela liberdade e segurança dos indivíduos em relação ao Estado, ou seja, dizem respeito às liberdades públicas e direitos políticos traduzidos pela liberdade.

Ademais, a partir do século XIX, diante do contexto da Revolução Industrial europeia e da fixação dos direitos sociais, surgem os direitos da segunda geração (LENZA, 2019), relacionados às conquistas trabalhistas e econômicas. $\mathrm{O}$ Estado passa a ser garantidor de direitos na medida em que detém o dever de tutelar o bem-estar do ser humano, garantindo condições básicas para a vida em sociedade. Os direitos de segunda geração, portanto, concentram-se na relevância dos direitos sociais, culturais e econômicos, ou seja, nos direitos coletivos, acentuando o princípio da igualdade.

Os direitos fundamentais da terceira geração surgem em um contexto de profundas mudanças na comunidade internacional (sociedade de massa crescente em desenvolvimento tecnológico e científico). Identifica-se uma categoria de direitos relacionada não mais ao indivíduo e sim à coletividade, numa perspectiva de universalidade na qual surgem os direitos difusos. São os denominados direitos de solidariedade ou fraternidade, que englobam o direito ao meio ambiente equilibrado - objeto de discussão do presente trabalho -, direito à sadia qualidade de vida, direito à paz, à comunicação e dentre outros.

Destarte, Ferreira Filho (2006) preceitua a primeira geração como a dos direitos de liberdade; já a segunda representa os direitos de igualdade, enquanto a terceira, a solidariedade, 


\section{ARTIGO}

INOVAÇÃo

o que acompanha o lema da Revolução Francesa: liberdade, igualdade, fraternidade. Ainda, algumas doutrinas defendem a existência de uma quarta geração de direitos baseadas na doutrina de Bobbio (1992). Nela, os direitos decorrem da globalização dos direitos fundamentais, correspondendo a fase de institucionalização do Estado social, destacando-se os direitos à democracia direta, informação e pluralismo (LENZA, 2019).

Nesse contexto, dentro dos direitos fundamentais relacionados à uma perspectiva universal, englobando os direitos difusos, destaca-se o direito ao meio ambiente equilibrado como essencial e garantidor do direito à vida, tendo como princípio norteador a proteção e defesa do meio ambiente em prol das gerações atuais e futuras.

Direitos fundamentais são identificados quando positivados em textos constitucionais com cláusulas de exigibilidade, nas quais a sociedade tem o direito e o Estado, por meio de seus órgãos e organismos, tem o dever de garantir e assegurar o cumprimento dos direitos humanos que foram ali escritos. Isso decorre de compromissos assumidos pelos Estados em âmbito internacional, ou seja, de convenções e declarações de princípios que orientam a aplicabilidade de proteção de direitos (BONAVIDES, 2018).

O meio ambiente ecologicamente equilibrado foi determinado constitucionalmente como direito fundamental de tríplice dimensão: individual, social e intergeracional. É um direito individual porque compreende a cada indivíduo a vida sadia; é social considerando que o meio ambiente é um direito de todos, integrando o patrimônio coletivo; e é intergeracional, pois é um direito que necessita de integração e compreensão de gerações futuras e atuais para a preservação do ambiente.

A determinação constitucional do meio ambiente como direito fundamental está elencada no artigo 225, caput, da Constituição Federal, em que: "Todos têm direito ao meio ambiente ecologicamente equilibrado, bem de uso comum do povo e essencial à sadia qualidade de vida, impondo-se ao Poder Público e à coletividade o dever de defendê-lo e preservá-lo para as presentes e futuras gerações" (BRASIL, 1988, online).

A legislação ambiental brasileira com o objetivo de preservar o equilíbrio ambiental é relativamente recente, ainda que a utilização de recursos naturais seja intuito de regulamentação desde o período colonial. Há tempos, as riquezas do meio ambiente eram consideradas como bens de consumo para a sociedade ou insumos nos processos produtivos (MILARÉ, 2013). Outrora essa situação foi alterada e atualmente o país possui uma legislação ambiental considerada avançada em diversos aspectos, inclusive no que tange à educação e informação, conforme se verifica na próxima seção. 


\section{ARTIGO}

INOVAÇÃo

\section{O PRINCÍPIO DA INFORMAÇÃO NA SEARA AMBIENTAL}

O princípio da informação ambiental orienta a implementação do direito à informação elencado no artigo $5^{\circ}$, incisos XIV e XXXIII da Constituição Federal, que prescrevem que todos os indivíduos detêm o direito a ter acesso às informações públicas, de interesse particular ou coletivo, devendo estas ser prestadas no prazo da lei, sob pena de responsabilidade, com exceção dos casos de sigilo relacionados à segurança da sociedade e do Estado (BRASIL, 1988).

De acordo com Machado (2013), o direito à informação é de cada indivíduo e de todos, significando que a informação pode ser originada tanto da esfera pública quanto da privada. De modo que compreende-se por informação pública aquela que não se encontra na zona de intimidade e da vida privada do agente, somada sua imagem e honra, hipóteses que sustentam o sigilo de determinados casos.

Na Constituição Federal de 1988, artigo 220, caput, é assegurada a manifestação do pensamento, a criação, a expressão e a informação, sob qualquer forma, processo ou veículo, sem restrição. Sustenta-se, assim, que o direito à informação é absoluto, não enfrentando restrição, salvo no que tange à matéria sigilosa outrora mencionada. Assim, todos os cidadãos possuem o direito de informar, de ser informados e de acessar informações, de acordo com os três níveis que compõem o objeto normativo do direito à informação (CANOTILHO, 1992). Ainda, no artigo 225, caput, a Constituição Federal assevera que é imposto ao Poder Público e à coletividade o dever de defender e preservar o meio ambiente para as presentes e futuras gerações. Desse modo, a proteção do meio ambiente só é possível de ser efetivada com a participação da coletividade como um todo, o que acarreta extrema importância da informação.

A Lei de Acesso à Informação (LAI), aprovada em 2011 (Lei Federal No 12.527), protege e intitula esse direito à informação, e coaduna que deve ser garantido e observado pela União, Estados, Distrito Federal e Municípios, tudo em consonância com a Carta Magna. De acordo com o artigo $4^{\circ}$, inciso I da Lei de Acesso à Informação, considera-se informação como dados, processados ou não, que podem ser utilizados para produção e transmissão de conhecimento (BRASIL, 2011).

A informação é fator vital para a subsistência dos indivíduos e da sociedade, enquanto ordem e estrutura, de modo que um dos pontos fundamentais e evidentes do grau de desenvolvimento de uma sociedade é a qualidade da informação disponível para os indivíduos (SARACEVIC, 1974). Neste sentido, ensina Milaré (2014, p. 219) que "os cidadãos com acesso à informação têm melhores condições de atuar sobre a sociedade, de articular mais 
eficazmente", o que qualifica a participação popular em processos decisórios. Logo, destaca-se a importância do acesso à informação, principalmente da coletividade ante o Poder Público, no que tange aos temas de interesse coletivo, como a informação ambiental.

O princípio da informação é reconhecido como um princípio geral do direito ambiental brasileiro, juntamente com os princípios da participação, da prevenção, da precaução, da reparação e do poluidor-pagador (BRASIL, 2004). Atualmente agrega-se a estes outros princípios, como o do protetor-recebedor e do usuário-pagador, que igualmente orientam a implementação da política ambiental nacional e se materializam veiculando informações ambientais. O princípio da informação é a alma do direito fundamental previsto no ordenamento jurídico, expressamente no artigo $5^{\circ}$ da Constituição Federal, que visa garantir o acesso à informação, possibilitando, assim, que os indivíduos se conscientizem sobre as políticas ambientais por meio do Direito à Informação.

A informação ambiental está ligada à liberdade da comunicação social quanto à compreensão das condições ambientais existentes. Neste sentido, Fiorillo (2013, p. 72-73) ressalta que:

a informação ambiental é corolário do direito de ser informado, previsto nos arts. 220 e 221 da Constituição Federal. O citado art. 220 engloba não só o direito à informação, mas também o direito a ser informado (faceta do direito de antena), que se mostra como um direito difuso [...].

Destarte, a Declaração do Rio de Janeiro Sobre Meio Ambiente e Desenvolvimento de 1992, princípio 10, estabelece que:

no nível nacional, cada indivíduo deve ter acesso adequado à informações relativas ao
meio ambiente de que disponham autoridades públicas, inclusive informações sobre
materiais e atividades perigosas em suas comunidades, bem como a oportunidade de
participar em processos de tomada de decisões. Os Estados devem facilitar e estimular
a conscientização e a participação pública, colocando a informação à disposição de
todos. Deve ser propiciado acesso efetivo a mecanismos judiciais e administrativos,
inclusive no que diz respeito à compensação e reparação de danos (ONU, 1992, não
paginado).

Segundo Machado (2013), o meio ambiente possui uma relação inegável com o direito dos indivíduos de serem informados, considerando a Declaração mencionada anteriormente e os documentos internacionais, tais como: a Convenção sobre o Acesso à Informação, a Participação do Público no Processo Decisório e o Acesso à Justiça em Matéria de Meio Ambiente - Aarhus, Dinamarca, em 1998, Primeira Conferência Europeia sobre Meio Ambiente e Saúde - Frankfurt, Alemanha, em 1989, e a Declaração de Limoges - França, em 2005.

O direito à informação é um direito fundamental previsto na Carta Magna, que visa situar e educar os indivíduos sobre a realidade existente e, principalmente na seara ambiental, 
possibilitar uma cooperação social, a fim de resguardar o meio ambiente como bem de uso comum. De acordo com Machado (2013, p. 123), “a informação serve para o processo de educação de cada pessoa e da comunidade. Mas a informação visa, também, a dar chance à pessoa informada de tomar posição ou pronunciar-se sobre a matéria informada". Sendo assim, é possível afirmar que a educação ambiental dos indivíduos está ligada a informação, aos dados que lhes são noticiados.

O objetivo da informação consiste na participação ativa dos indivíduos, na esfera individual e pública, quanto aos assuntos relacionados ao meio ambiente e seu equilíbrio. Desse modo, vale ressaltar que a educação ambiental é de extrema importância para que a finalidade da informação seja efetivada, haja vista que

educar ambientalmente significa: a) reduzir os custos ambientais, à medida que a
população atuará como guardiã do meio ambiente; b) efetivar o princípio da
prevenção; c) fixar a ideia de consciência ecológica, que buscará sempre a utilização
de tecnologias limpas; d) incentivar a realização do princípio da solidariedade, no
exato sentido que perceberá que o meio ambiente é único, indivisível e de titulares
indetermináveis, devendo ser justa e distributivamente acessível a todos; e) efetivar o
princípio da participação, entre outras finalidades (FIORILLO, 2011, p. 126).

Verifica-se que o princípio da informação ambiental visa proporcionar uma educação aos indivíduos, na medida em que transmite informações, a fim de que seja alcançado um conhecimento acerca da real situação ambiental das comunidades, bem como na conscientização sobre condutas responsáveis para preservação do meio ambiente. A informação ambiental pode ser gerencial, auxiliando a administração dos ambientes, ou políticoeducacional, na medida que contribui para a percepção da realidade e atuação cidadã em relação a sociedade e ao ambiente natural (CARIBÉ, 1992; TARGINO apud VASCONCELOS, 1998), dependendo de diversos fatores.

Tavares e Freire (2003) preceituam que a informação ambiental é um tipo de informação científica e tecnológica de suma importância para superação da crise ambiental que vivenciamos atualmente, auxiliando para a preservação de ambientes naturais, bem como daqueles construídos pelo homem. Entretanto, os profissionais da informação devem procurar facilitar a difusão da informação ambiental, contribuindo para o desenvolvimento autossustentável do Brasil.

Segundo diversos autores como Freeman, Somerville e Dave (apud CARIBÉ, 1992), as principais características da informação ambiental são a inter e multidisciplinaridade, considerando que para se desenvolver estudos sistemáticos na área são imperiosos parâmetros e definições pertencentes a diversas ramificações da ciência e tecnología. Somerville (apud CARIBÉ, 1992, p. 2) indica características da informação ambiental, tais como: 
a) os dados ambientais quase sempre são publicados, e o conhecimento de sua existência só será possível após longa e/ou exaustiva experiência na área; b) grande quantidade de informações e dados relevante aparece em publicações que não são indexadas ou o são inadequadamente; c) grande quantidade de informações produzidas e/ou coletadas por empresas privadas ou pelo governo não está disponível ao público, nem tampouco foi processada; d) os dados disponíveis são duvidosos no que se refere à qualidade e validade, uma vez que os métodos de coleta não são padronizados nem amplamente conhecidos; e) a informação é passível de manipulação por pressões políticas, considerações emocionais ou conservacionistas, ou ainda pressões de grupos econômicos; f) rápida obsolescência dos dados e da literatura; g) insuficiência de fontes e de obras de referência que indiquem informações publicadas; h) urgência da demanda da informação para a ação do usuário; i) área onde os colégios invisíveis não são estáticos.

Há uma necessidade de formação de uma consciência ambiental, de busca à preservação ao meio ambiente equilibrado, de um contexto no qual a sociedade e o poder público, unidos, promovam a tutela coletiva do meio ambiente. O poder público deve atentar para a importância da informação e sua efetivação, pincipalmente no que tange à ocorrência de danos quanto a determinadas atividades realizadas pela coletividade que atingem diretamente a manutenção da proteção ambiental.

Sem informação não é possível compreender as condições ambientais existentes, reduzindo a atuação do Estado frente às políticas públicas ambientais contra danos, e tampouco é possível que os indivíduos sejam inteirados sobre a sua atuação e como devem pautar suas condutas de modo correto. Faz-se necessária a construção de uma consciência prévia dos cidadãos, promovida pelo fornecimento de informações, a fim de que sejam formadas consciências ambientais, estimuladas pelo poder público visando o desenvolvimento sustentável.

O desenvolvimento sustentável, consistente no desenvolvimento apto a suprir as necessidades da geração atual, numa perspectiva de finitude dos recursos naturais, pressupondo a preocupação com gerações futuras, é fruto de um debate considerado recente. $\mathrm{O}$ discurso relacionado à. preocupação com o meio ambiente é tido como atual, onde a percepção da crise ambiental resultante da exploração desmedida dos recursos naturais e os desníveis sociais decorrentes do aumento populacional, foram alguns dos fatos que ensejaram a busca pelo modelo de desenvolvimento sustentável a partir da década de 70 (CARIBÉ, 1992).

No Brasil, até a década de 1970, verifica-se um desinteresse pela questão ambiental, decorrente do reduzido número de desastres naturais e pela incipiente atuação das organizações ambientalistas no país. Prevalecia a convicção de incompatibilidade entre o crescimento econômico e a questão ambiental, o que levou ao estímulo do crescimento de exportações e à atração de investimento internacional, visando o país como um local sem limitações ambiental (VASCONCELOS, 1998). 
A Conferência das Nações Unidas para o Meio Ambiente Urbano, ocorrida em 1972 em Estocolmo, expôs a posição brasileira quanto ao crescimento econômico e à redução da poluição, acarretando as primeiras determinações sobre a informação ambiental. Foi criado pelo governo um novo órgão ambiental, a Secretaria Especial de Meio Ambiente, órgão de assessoria especial da Presidência da República, objetivando o combate à poluição e proteção dos recursos naturais do país (CARIBÉ, 1992). Registre-se também que, em 1974 e em 1980, foram aprovados planos nacionais de desenvolvimento que internalizaram a perspectiva da compatibilização do desenvolvimento econômico, com a utilização dos recursos naturais e a qualidade de vida.

Em 1981 é aprovada a Política Nacional de Meio Ambiente (PNMA), Lei Federal No 6.938/81, com o objetivo de preservar, melhorar e recuperar a qualidade ambiental propícia à vida, visando assegurar as condições para o desenvolvimento socioeconômico, os interesses da segurança nacional e a proteção da dignidade da vida humana (BRASIL, 1981). Tal política é considerada um marco legal, haja vista que elaborou a sistemática das políticas públicas para o meio ambiente no Brasil.

Dentre os objetivos da PNMA listados no artigo $4^{\circ}$, inciso V, está a difusão de tecnologias de manejo do meio ambiente, a divulgação de dados e informações ambientais e a formação de uma consciência pública sobre a necessidade de preservação da qualidade ambiental e do equilíbrio econômico. Para alcançar essa meta, a PNMA criou os denominados instrumentos de política ambiental, dentre eles o Sinima, responsável pela gestão da informação ambiental no âmbito do Sistema Nacional de Meio Ambiente (Sisnama) (BRASIL, 1981).

O Sinima foi instituído pelo artigo $9^{\circ}$, VII, da Lei 6.938/81, com a finalidade de estruturar as informações necessárias ao apoio dos órgãos ambientais para a captura de decisões nas mais diversas áreas. Constitui um instrumento de gestão da informação dos órgãos do Sisnama, compartilhando a gestão ambiental na esfera dos Poderes Legislativo, Executivo e Judiciário. Destaca-se que o sistema é coordenado pela Secretaria Executiva do Ministério do Meio Ambiente, estabelecida pelo Decreto $n^{\circ}$ 5.776/2006, e recebe o apoio do Comitê Gestor do Sinima, formado pela Portaria n ${ }^{\circ} 310$, de 13/12/2014.

Conforme aduz Milaré (2014), o uso da informação serve a inúmeros objetivos, como a detecção do problema, o encontro de medidas para a sua solução, bem como o monitoramento do cumprimento de tais medidas. E é nesta esfera que o Sistema Nacional de Informações sobre o Meio Ambiente deve atuar, organizando informações com o intuito de auxiliar na proteção ao meio ambiente. 
INOVAÇÃo

\section{A INFORMAÇÃO AMBIENTAL NO CADASTRO AMBIENTAL RURAL E O PLANEJAMENTO DAS POLÍTICAS PÚBLICAS}

Atualmente o Sinima não se encontra ativo em uma página própria, estando disponível apenas dentro do link "informações ambientais" no Portal do Ministério do Meio Ambiente. Lehfeld, Carvalho e Balbim (2013) afirmam que o Sinima é um instrumento de sistematização de informações ambientais, contando com as mais diversas ramificações para o exercício dessa importante função. Sendo assim, neste contexto de organização e compartilhamento de informações ambientais, o Código Florestal de 2012 instituiu o Cadastro Ambiental Rural (CAR).

O CAR é um instrumento de registro eletrônico obrigatório para todos os imóveis rurais, no qual se identifica a situação ambiental da área de posses e propriedades rurais, compondo uma base de dados para controle, monitoramento, planejamento ambiental e econômico e combate ao desmatamento, conforme disposto no artigo 29 do Novo Código Florestal brasileiro (BRASIL. Lei $\left.\mathrm{n}^{0} 12.651,2012\right)$. O propósito do cadastro é gerar e fornecer informações acerca da tutela ambiental para a população em promoção ao desenvolvimento sustentável e à formulação de políticas públicas ambientais.

Ademais, com o fito de regulamentar a atuação do CAR e o compartilhamento de informações, o Decreto Federal n ${ }^{\circ}$ 7.830/2012 criou o Sistema Nacional de Cadastro Ambiental Rural (Sicar), que é um sistema eletrônico de âmbito nacional destinado à integração e ao gerenciamento de informações ambientais dos imóveis rurais de todo o País, conforme disposto no art. $2^{\circ}$. De acordo com a legislação federal, o Sicar possui viés informativo, sendo possível identificar todas as características do imóvel rural, oportunizando a formação da opinião da sociedade, por meio da conscientização dos dados ambientais, por intermédio de acesso livre e público, como a informação ambiental deve ser.

Para o cenário ambiental da Amazônia brasileira, com grandes ocorrências de graves problemas ambientais tais como o desmatamento e situações de grilagem de terra, as informações constantes no Sicar são importantes para adoção de políticas públicas ambientais preventivas e repressivas. Neste sentido, é necessário promover a implementação total do CAR em todo o território, num contexto de compartilhamento de informações, com uma base de dados eficiente e confiável, a fim de auxiliar a políticas públicas que incentivam a manutenção do equilíbrio ambiental como expressão do desenvolvimento sustentável.

O Ministério do Meio Ambiente (MMA) aprovou em 2014 e passou a implementar a Política de Integração e Segurança da Informação (Pisi) do Cadastro Ambiental Rural, por 
intermédio da Instrução Normativa $n^{\circ} 2$ e no 3/2014, implementando disposições contrárias aos intentos da PNMA e do Sinima, conforme exposto em seus artigos a seguir:

Art. $2^{\circ}$ As informações do Cadastro Ambiental Rural - CAR armazenadas no SICAR se destinam a subsidiar políticas, programas, projetos e atividades de controle, monitoramento, planejamento ambiental e econômico e combate ao desmatamento. Parágrafo único. Em casos de danos causados à segurança nacional ou a terceiros pelo uso das informações do SICAR com finalidades diferentes das previstas neste artigo, os usuários poderão ser responsabilizados nas esferas administrativa, civil e penal.

Art. $3^{\circ}$ As informações com restrições de acesso no SICAR serão aquelas definidas como sigilosas ou pessoais, na forma da Lei n o 12.527, de 18 de novembro de 2011, e da Lei $\mathrm{n}^{\circ} 5.172$, de 25 de outubro de 1966, sem prejuízo da observância de outros diplomas legais e regulamentares disponentes sobre sigilo e restrições ao acesso à informação.

Art. $4^{\circ}$ As informações sobre o patrimônio das pessoas físicas e jurídicas armazenadas no SICAR, a serem protegidas pelo sigilo fiscal previsto no art. 198 da Lei $\mathrm{n}^{\circ} 5.172$, de 25 de outubro de 1966, de acordo com os incisos I, II e III do art. 2 o da Portaria RFB n o 2.344, de 24 de março de 2011, incluem: I - as que identifiquem os proprietários ou possuidores e suas respectivas propriedades ou posses, tais como $\mathrm{CPF}$, CNPJ, nome, endereço físico e de correio eletrônico; II - as que associem as propriedades ou posses a seus respectivos proprietários ou possuidores, configurando relações patrimoniais; III - as que associem meios de produção ou resultados de produção agrícola ou agroindustrial de imóvel rural específico a seus respectivos proprietários ou possuidores; e IV - outras informações de natureza patrimonial (BRASIL, 6 maio 2014, 18 dez. 2014).

Sendo assim, verifica-se uma incongruência de normas, haja vista que uma lei federal regulamenta o acesso público aos dados dos órgãos pertencentes ao Sisnama e a uma instrução normativa institui restrição de acesso a informações constantes no Cadastro Ambiental Rural. Ressalte-se que a instrução normativa contraria dispositivos constitucionais e a própria finalidade do CAR como integrante do Sinima.

Há uma dualidade de posições defendidas. De um lado, a Confederação da Agricultura e Pecuária do Brasil (CNA) afirma que a ampla divulgação das informações dos imóveis rurais, inclusive sobre quem é o titular do imóvel rural, acaba por colocar em risco a segurança dos agricultores, podendo afetar também a competitividade internacional do Brasil; de outro, o Observatório do Código Florestal afirma que o amplo acesso às informações contidas no CAR é necessário para efetividade do Código Florestal, pois a transparência é fundamental para a implementação de políticas públicas (PIRES, 2017).

A restrição de acesso a informações enseja diversas dificuldades a serem enfrentadas pela sociedade, principalmente no combate aos danos ambientais. Desta forma, é importante que as informações constantes no CAR sejam fornecidas a todos para serem utilizadas na criação de políticas públicas com o objetivo principal de diminuir impactos ambientais e contribuir para fomentar a proteção da fauna e flora brasileira. 
O CAR diz respeito a um sistema de registro que qualifica os imóveis rurais, devendo conter todos os dados pertencentes a estes, inclusive a identificação do proprietário e sua atividade. Segundo Fonseca e Silva (2015, p.474):

\footnotetext{
a dificuldade no acesso à informação sobre o titular do imóvel significa dificultar a informação sobre eventual responsável pelo dano ambiental ou sujeito passivo das obrigações ambientais, que podem ser exigidas por qualquer interessado por meio de ação popular.
}

Nos estados pertencentes à Amazônia legal é ainda mais significativa, haja vista que o grande problema a ser enfrentado é o desmatamento, e para realizar tal ato faz-se necessária a utilização de informações para diminuir os impactos causados pelo ato e combatê-lo, considerando que não é possível a adoção de políticas públicas sem o acesso a informações. Logo, a informação sempre deve ser fornecida de forma mais clara possível, por intermédio de mapeamentos e identificações das áreas, com o zoneamento destas, utilizando muita tecnologia, para auxiliar a criação de políticas públicas voltadas para a proteção do meio ambiente e combate ao desmatamento, com informações precisas.

\section{CONSIDERAÇÕES FINAIS}

O sistema jurídico de proteção ambiental consagrado pela Constituição da República Federativa do Brasil de 1988 tratou da proteção ao meio ambiente ecologicamente equilibrado como um direito fundamental, que deve ser garantido pelo poder público e pela coletividade, cabendo à legislação ambiental infraconstitucional o dever de regulamentar a matéria de acordo com as disposições constitucionais.

O Código Florestal de 2012 trouxe avanços significativos objetivando a proteção do meio ambiente, dentre eles a implementação de um importante instrumento de informação ambiental das propriedades e posses rurais, viabilizando o planejamento, controle e monitoramento do passivo ambiental, qual seja o Cadastro Ambiental Rural.

A inscrição no CAR é exigência para a regularização do imóvel rural, concessão da licença ambiental e oportuniza o acesso a uma série de benefícios dispostos na Lei $\mathrm{n}^{\circ}$ 12.651/2012, dentre eles a possibilidade de aderir ao Programa de Regularização Ambiental (PRA) e acessar crédito rural e demais programas oficiais de incentivo à produção. Por outro lado, o CAR proporciona ao poder público informações constantes no cadastro que possibilitam identificar o passivo de reserva legal, áreas de preservação permanente e áreas de uso restrito dos imóveis rurais. 
Alcançar o objetivo do cadastro, de integrar informações ambientais dos imóveis rurais, compondo base de dados para controle, monitoramento, planejamento ambiental e econômico e combate ao desmatamento, só é possível se os dados forem acessíveis. A regulamentação infraconstitucional e a implementação do Sicar propiciam um ambiente conflituoso em relação à transparência de informações, ao passo que as regulamentações infralegais contradizem a Lei de Acesso a Informações Públicas.

O princípio da informação é de extrema importância para a efetividade da finalidade do CAR e a implementação de políticas públicas voltadas a proteção do meio ambiente. Tais políticas concentram no combate e prevenção das ações que prejudiquem o meio ambiente e só são efetivadas com informações adequadas e amplas, demonstrando, assim, a importância da credibilidade de tal cadastro e da informação ambiental. 


\section{REFERÊNCIAS}

BOBBIO, Norberto. A era dos direitos. Tradução Carlos Nelson Coutinho. Rio de Janeiro: Campos, 1992.

BONAVIDES, Paulo. Curso de direito constitucional. 34. ed. rev., atual. e ampl. São Paulo: Malheiros, 2018.

BRASIL. [Constituição (1988)]. Constituição da República Federativa do Brasil. Brasília, DF: Presidência da República, [2020]. Disponível em:

http://www.planalto.gov.br/ccivil_03/constituicao/ConstituicaoCompilado.htm. Acesso em: 9 set. 2020.

BRASIL. Decreto $\mathbf{n}^{0}$ 5.098, de 03 de junho de 2004. Dispõe sobre a criação do Plano Nacional de Prevenção, Preparação e Resposta Rápida a Emergências Ambientais com Produtos Químicos Perigosos - P2R2, e dá outras providências. Brasília, DF: Presidência da República, 2004. Disponível em: http://www.planalto.gov.br/ccivil_03/_Ato20042006/2004/Decreto/D5098.htm. Acesso em: 24 set. 2020.

BRASIL. Decreto $\mathbf{n}^{\mathbf{0}} \mathbf{7 . 8 3 0}$, de 17 de outubro de 2012. Dispõe sobre o Sistema de Cadastro Ambiental Rural, o Cadastro Ambiental Rural, estabelece normas de caráter geral aos Programas de Regularização Ambiental, de que trata a Lei no 12.651, de 25 de maio de 2012, e dá outras providências. Brasília, DF: Presidência da República, 2012. Disponível em: http://www.planalto.gov.br/ccivil_03/_Ato2011-2014/2012/Decreto/D7830.htm. Acesso em: 13 set. 2020.

BRASIL. Lei $\mathbf{n}^{\mathbf{0}}$ 12.527, de 18 de novembro de 2011. Regula o acesso a informações previsto no inciso XXXIII do art. $5^{\circ}$, no inciso II do $\S 3^{\circ}$ do art. 37 e no $\S 2^{\circ}$ do art. 216 da Constituição Federal; altera a Lei $n^{\circ} 8.112$, de 11 de dezembro de 1990; revoga a Lei ${ }^{\circ}$ 11.111, de 5 de maio de 2005, e dispositivos da Lei no 8.159, de 8 de janeiro de 1991; e dá outras providências. Brasília, DF: Presidência da República, 2011. Disponível em: http://www.planalto.gov.br/ccivil_03/_ato2011-2014/2011/lei/112527.htm. Acesso em: 11 set. 2020.

BRASIL. Lei $\mathbf{n}^{\mathbf{0}} \mathbf{1 2 . 6 5 1}$, de 25 de maio de 2012. Dispõe sobre a proteção da vegetação nativa; altera as Leis $n^{\circ} 6.938$, de 31 de agosto de 1981, 9.393, de 19 de dezembro de 1996, e 11.428, de 22 de dezembro de 2006; revoga as Leis $\mathrm{n}^{\circ}$ 4.771, de 15 de setembro de 1965, e 7.754, de 14 de abril de 1989, e a Medida Provisória n 2.166-67, de 24 de agosto de 2001, e dá outras providências. Brasília, DF: Presidência da República, 2012. Disponível em http://www.planalto.gov.br/ccivil_03/_ato2011-2014/2012/lei/L12651compilado.htm. Acesso em: 9 set. 2020.

BRASIL. Lei $\mathbf{n}^{\mathbf{0}}$ 6.938, de 31 de agosto de 1981. Dispõe sobre a Política Nacional do Meio Ambiente, seus fins e mecanismos de formulação e aplicação, e dá outras providências. Brasília, DF: Presidência da República, 1981. Disponível em: http://www.planalto.gov.br/ccivil_03/leis/16938.htm. Acesso em: 13 set. 2020.

BRASIL. Ministério do Meio Ambiente. Instrução Normativa 2/MMA. Brasília, DF: Ministério do Meio Ambiente, 6 maio 2014. Disponível em:

http://www.car.gov.br/leis/IN_CAR.pdf. Acesso em: 8 set. 2020. 
BRASIL. Ministério do Meio Ambiente. Instrução Normativa 3/MMA. Brasília, DF: Ministério do Meio Ambiente, 18 dez. 2014. Disponível em: http://www.car.gov.br/leis/IN_CAR_3.pdf. Acesso em: 9 set. 2020.

CANOTILHO, José Joaquim Gomes. Direito constitucional. 5. ed. Coimbra: Almedina, 1992.

CARIBÉ, Rita de Cássia do Vale. Subsídios para um sistema de informação ambiental no Brasil. Ciência da informação, Brasília, DF, v. 21, n.1, p. 40-45, jan./abr. 1992.

FERREIRA FILHO, Manoel Gonçalves. Direitos humanos fundamentais. 7. ed. São Paulo: Saraiva, 2006.

FIORILLO, Celso Antonio. Curso de direito ambiental brasileiro. 14. ed. São Paulo: Saraiva, 2013.

FIORILLO, Celso Antonio. Curso de direito ambiental brasileiro. São Paulo: Saraiva, 2011.

FONSECA, Luciana Costa da; SILVA, Danielle Fonseca. A proteção ambiental rural como direito à informação e o sigilo de dados. Revista Jurídica, Curitiba, v. 4, n. 41, p. 461-478, 2015. Disponível em:

http://www.conpedi.org.br/publicacoes/c178h0tg/51f4alp5/3HUq63Pn8J2Bd0Mb.pdf. Acesso em: 29 set. 2020.

LEHFELD, L. de S.; CARVALHO, C. B. de; BALBIM, L. I. N. Código Florestal comentado e anotado. 2. ed. São Paulo: [s.n.], 2013.

LENZA, Pedro. Direito constitucional esquematizado. 23. ed. São Paulo: Saraiva Educação, 2019.

MACHADO, Paulo Afonso Leme. Direito ambiental brasileiro. 21. ed. São Paulo: Malheiros, 2013.

MILARÉ, Edis. Direito do ambiente. 9 ed. São Paulo: Revista dos Tribunais, 2014.

MILARÉ, Édis; MACHADO, Paulo Afonso Leme (Coord.). Novo Código Florestal. 2. ed. São Paulo: Revista dos Tribunais, 2013.

ONU. Declaração do Rio sobre meio ambiente e desenvolvimento. Rio de Janeiro: [ONU], 1992. Disponível em: https://cetesb.sp.gov.br/proclima/wpcontent/uploads/sites/36/2013/12/declaracao_rio_ma.pdf. Acesso em: 09 set. 2020.

PIRES, Victor. Falta de transparência do CAR coloca em xeque objetivos do Código Florestal. [São Paulo]: Instituto Socioambiental, 2017. Disponível em: https://www.socioambiental.org/pt-br/noticias-socioambientais/falta-de-transparencia-do-carcoloca-em-xeque-objetivos-do-codigo-florestal. Acesso em: 23 set. 2020.

SARACEVIC, Tefko. Tecnologia da Informação, sistemas de informação como utilidade pública. Ciência da informação, Rio de Janeiro, v. 3, n. 1, p. 57-67, 1974. Disponível em: http://revista.ibict.br/ciinf/article/view/41/41. Acesso em: 23 set. 2020. 


\section{ARTIGO}

- INOVAÇÃo

SILVA, José Afonso da. Direito ambiental constitucional. 11. ed. atual. São Paulo: Malheiros, 2019.

TAVARES, Carla; FREIRE Isa Maria. Informação ambiental no Brasil: para quê e para quem. Perspect. cienc. inf., Belo Horizonte, v. 8, n. 2, p. 208-215, jul./dez. 2003.

VASCONCELOS, C. R. de. O papel das ONGs brasileiras na produção e disseminação de informação ambiental. 1998. Dissertação (Mestrado em Ciência da Informação) - Instituto Brasileiro de Informação em Ciência e Tecnologia, Universidade Federal do Rio de Janeiro, Rio de Janeiro, 1998. 